\title{
Specific features of the response of the antioxidant system of urban trees to mistletoe infection
}

\author{
Liubov Skrypnik*, Pavel Maslennikov, Pavel Feduraev, Atrem Pungin, and Nikolay Belov \\ Institute of Living Systems, Immanuel Kant Baltic Federal University, Universitetskaya Str., 2, \\ 236038 Kaliningrad, Russia
}

\begin{abstract}
Urban green spaces are an important component of sustainable urban development. Infestation of urban trees by mistletoe white leads to a decrease in the growth energy of woody plants and their longevity. In the present study, the peculiarities of oxidative stress development and response of antioxidant enzymes (superoxide dismutase and catalase) of three tree species (Tilia cordata, Acer platanoides and Populus nigra) that are most susceptible to mistletoe infestation in Kaliningrad were studied. It was found that in all three species, when severely affected (more than 50 mistletoe bushes per tree), the bark content of malonic dialdehyde and hydrogen peroxide increased, indicating the intensification of oxidative processes in the cells of the affected trees. The catalase reaction was more pronounced compared to superoxide dismutase. The result confirms the fact that mistletoe infestation of trees leads to changes in redox metabolism in the cells of host trees and may indirectly lead to their weakening.
\end{abstract}

\section{Introduction}

Urban green spaces are an important component of the sustainable development of urbanized areas, performing various functions to ensure a comfortable environment. In particular, urban trees contribute to reducing air pollution, supporting biodiversity, mitigating heat island effects in cities, improving the aesthetics and attractiveness of urban areas, which ultimately also leads to improved human health [1]. At the same time, urban environmental conditions (limited water and nutrients, lack of sufficient space for roots and crowns, atmospheric air pollution) tend to adversely affect the growth of trees and make them more susceptible to biotic factors [2]. One of these factors is the infestation of urban trees with white mistletoe.

White mistletoe (Viscum album L.) is a semi-parasitic plant and is an evergreen, globular shrub that develops persistent haustoria in the host tree. Last year, for the first time, the authors conducted a study of the distribution of mistletoe white in the city of Kaliningrad. It was found that the main tree species susceptible to mistletoe infestation were Tilia cordata, Acer platanoides and Populus nigra. The analysis of ecological and

${ }^{*}$ Corresponding author: LSkrypnik@kantiana.ru 
landscape factors determining the distribution of mistletoe in the conditions of Kaliningrad showed that the leading factors determining the distribution of mistletoe white were the age of trees and relative air humidity [3].

Mistletoe infestation of trees leads to a decrease in the growth energy of woody plants and their longevity, causes partial or complete desiccation of the top and gradual drying out of the whole tree [4]. At the physiological level, the effect of mistletoe on trees is associated with the occurrence of water deficiency, disturbance of mineral nutrition, extraction of carbohydrates (glucose, fructose, sucrose) from the xylem fluid of the host tree [5]. Such changes, along with the action of other unfavorable factors of the urban environment, can lead to the oxidative process intensification in tree cells due to an increase in the level of reactive oxygen species.

The goal of this study was to investigate the peculiarities of oxidative stress development and response of antioxidant enzymes in heart-shaped linden (Tilia cordata Mill.), maple (Acer platanoides L.) and black poplar (Populus nigra L.) trees to their damage by white mistletoe (Viscum album L. subsp. album).

\section{Materials and Methods}

Branches of trees affected by mistletoe (Viscum album L. subsp. album) were used as study's objects. Tree species characterized by the most frequent mistletoe infestation in urban conditions - heart-shaped linden (Tilia cordata Mill.), maple (Acer platanoides L.) and black poplar (Populus nigra L.) were chosen for the study. For each species, sampling was conducted from trees with heavy mistletoe damage (more than 50 mistletoe bushes per tree), from trees with low mistletoe damage (less than 10 bushes per tree), and from trees without mistletoe damage (control trees). The samples were taken between October and December 2020. Several branches were taken from one tree, on which mistletoe bushes were present. The bark used for the study included the cambium, inner bark layer, and cortex. The selected samples were crushed and stored at a temperature of $-20{ }^{\circ} \mathrm{C}$ before analysis.

The malonic dialdehyde content was determined by reaction with thiobarbituric acid as described in [6] with some modifications. Homogenization of plant material $(0.5 \mathrm{~g})$ was performed in a mixture of $20 \%$ polyvinylpyrrolidone and $0.1 \%$ trichloroacetic acid in an ice bath. The homogenate was centrifuged at $20000 \mathrm{~g}$ for $25 \mathrm{~min}$ at $4{ }^{\circ} \mathrm{C}$. The supernatant was added to a $0.5 \%$ thiobarbituric acid solution in $20 \%$ trichloroacetic acid solution and incubated in a water bath at $95{ }^{\circ} \mathrm{C}$ for $30 \mathrm{~min}$. Next, the reaction was stopped by placing the tubes in ice for 10 minutes. The mixture was centrifuged at $10000 \mathrm{~g}$ for 10 minutes. Optical absorbance of the supernatant was determined at 532 and $600 \mathrm{~nm}$. The content of malonic dialdehyde in the plant material was calculated using an extinction coefficient of $155 \mathrm{mM}^{-1}$ $\mathrm{cm}^{-1}$ and expressed in $\mu \mathrm{mol}$ per gram of dry weight.

The hydrogen peroxide content in the samples was determined according to [7]. Plant material was homogenized in trichloroacetic acid in an ice bath. The homogenate was centrifuged at $16000 \mathrm{~g}$ for $15 \mathrm{~min}$. The supernatant was added to the reaction mixture containing $10 \mathrm{mM}$ phosphate buffer ( $\mathrm{pH} 7.0)$ and $1 \mathrm{M} \mathrm{KI}$. The mixture was incubated in the dark for 1 hour. Optical absorption was measured at $390 \mathrm{~nm}$. The hydrogen peroxide content in the plant material was determined according to the calibration schedule and expressed in $\mathrm{mmol} \mathrm{H}_{2} \mathrm{O}_{2}$ per gram of dry weight.

To isolate antioxidant enzymes, frozen shoot samples (approximately $0.5 \mathrm{~g}$ ) were ground in liquid nitrogen and homogenized in $2.0 \mathrm{ml}$ of $100 \mathrm{mM} \mathrm{K}$, Na-phosphate buffer cooled to $0{ }^{\circ} \mathrm{C}$ and including sodium ethylenediaminetetraacetate at $0.1 \mathrm{mM}$ concentration and $1 \%$ polyvinylpyrrolidone solution. The resulting mixture was centrifuged at $12,000 \mathrm{~g}$ 
for $30 \mathrm{~min}$ at $4{ }^{\circ} \mathrm{C}$. The supernatant was used to determine the activity of antioxidant enzymes and protein content by the Bradford method.

Superoxide dismutase activity was determined by its ability to inhibit the photochemical reduction of nitroblue tetrazolium as described in [8] with some modifications. For the catalytic reaction, the resulting supernatant $(0.5 \mathrm{ml})$ was mixed with $63 \mathrm{mM}$ nitroblue tetrazolium solution, $13 \mathrm{mM}$ L-methionine solution, $0.1 \mathrm{mM}$ sodium ethylenediaminetetraacetate solution, and $0.05 \mathrm{M}$ sodium carbonate solution. When $20 \mu \mathrm{l}$ of $0.025 \%$ riboflavin solution was added, the reaction was initiated and proceeded under fluorescent lights $(18 \mathrm{~W})$. After 15 minutes of incubation, the reaction was stopped by placing the tubes with the reaction mixture in the dark. The optical density values were recorded at $560 \mathrm{~nm}$. The enzyme activity was expressed in units equal to the amount of the enzyme at which $50 \%$ inhibition of nitroblue tetrazolium photoreduction was observed, equivalent to $\mathrm{mg}$ of protein.

The catalase activity was determined by the decrease in optical absorption caused by the decomposition of hydrogen peroxide under the action of catalase found in extracts of plant samples [9]. For this purpose, $2.95 \mathrm{ml}$ of $50 \mathrm{mM} \mathrm{K}$, Na-phosphate buffer solution was added to $30 \mu \mathrm{l}$ of the supernatant prepared as described above. The reaction was initiated with $20 \mu \mathrm{l}$ of $0.6 \mathrm{M}$ hydrogen peroxide solution. A solution containing buffer, extract, and $20 \mu \mathrm{l}$ distilled water instead of hydrogen peroxide was used as a control. Optical density readings were measured at $240 \mathrm{~nm}$ for 2 minutes at 1 -second intervals. When calculating the catalase activity, an absorption coefficient of $39.4 \mathrm{mM}^{-1} \mathrm{~cm}^{-1}$ was used. The catalase activity was expressed in $\mu \mathrm{mol} \mathrm{H}_{2} \mathrm{O}_{2} /$ ( $\mathrm{min} \cdot \mathrm{mg}$ of protein)

The activity of all studied antioxidant enzymes was converted to $\mathrm{mg}$ of protein. A Shimadzu UV-3600 spectrophotometer (Shimadzu, Japan) was used for spectrophotometric analyses.

The obtained experimental data were statistically processed using analysis of variance and Tukey's test for assessing the reliability of differences between the variants of the experiment at a significance level of $p \leq 0.05$.

\section{Results and Discussion}

Studies of peculiarities of malonic dialdehyde (MDA) accumulation by different tree species showed that changes in the content of this component in twig bark tissues when trees were affected by mistletoe depended on plant species. The results of quantitative determination of malonic dialdehyde content are shown in Figure 1.

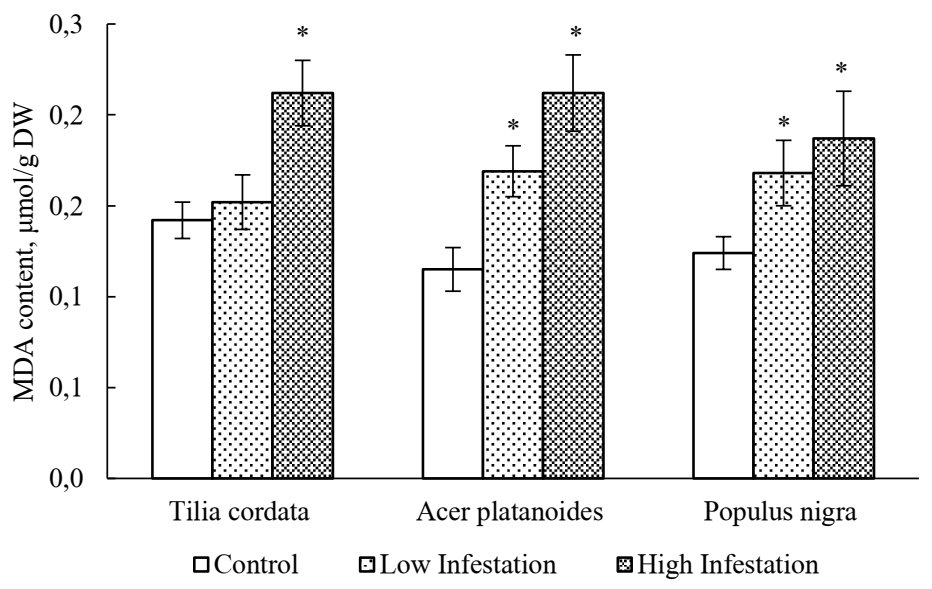


Fig. 1. The malonic dialdehyde content in the bark of control and mistletoe-infected trees of various species. * denotes significantly different mean values as compared to the control according to Tukey test at $p \leq 0.05$.

As can be seen from the data presented in Figure 1, a significantly higher level of malonic dialdehyde compared to the control was recorded in samples of trees of all three species studied, which were heavily affected by mistletoe. For trees of Acer platanoides and Populus nigra species, a higher level of malonic dialdehyde compared to the control was also detected in the bark of trees with a low degree of mistletoe infestation. Malondialdehyde is a product of lipid peroxidation. An increase in its level indicates the intensification of oxidative processes occurring in cells. It is known that the content of malonic dialdehyde increases when plants are exposed to various adverse factors of both biotic and abiotic nature. Thus, in [10], it was shown that infection of common pine (Pinus sylvestris L.) with mistletoe was associated with increased levels of malonic dialdehyde under drought conditions.

One of the indicators of the development in oxidative stress cells is the hydrogen peroxide content. Hydrogen peroxide refers to the active forms of oxygen arising from the incomplete one-electron reduction of oxygen to water. Hydrogen peroxide is an oxidizing agent of medium strength compared to other active oxygen forms, but can be a source of more reactive free radicals, in particular when interacting with ions of variable valence (e.g., $\mathrm{Fe}^{2+}, \mathrm{Cu}^{+}$) and hydrogen peroxide forms a hydroxyl radical that actively interacts with cell membranes and destroys them. The study's results of hydrogen peroxide content in the bark of different tree species depending on the degree of their mistletoe damage are shown in Figure 2.

In general, the change in the hydrogen peroxide content in the bark of branches of all the studied species when they were affected by mistletoe was similar to the change in the content of malonic dialdehyde. In samples of Tilia cordata and Populus nigra, a higher level of hydrogen peroxide was recorded only when trees were heavily infested, while in Acer platanoides, an increase in $\mathrm{H}_{2} \mathrm{O}_{2}$ was already observed when the degree of infestation was low. It should be noted that according to numerous studies conducted over the past few years, the hydrogen peroxide molecule can be considered not only as one of the active oxygen forms that cause cell damage, but also as a signaling molecule that plays an important role in regulating metabolic processes in living organisms, especially in the presence of adverse factors [11].

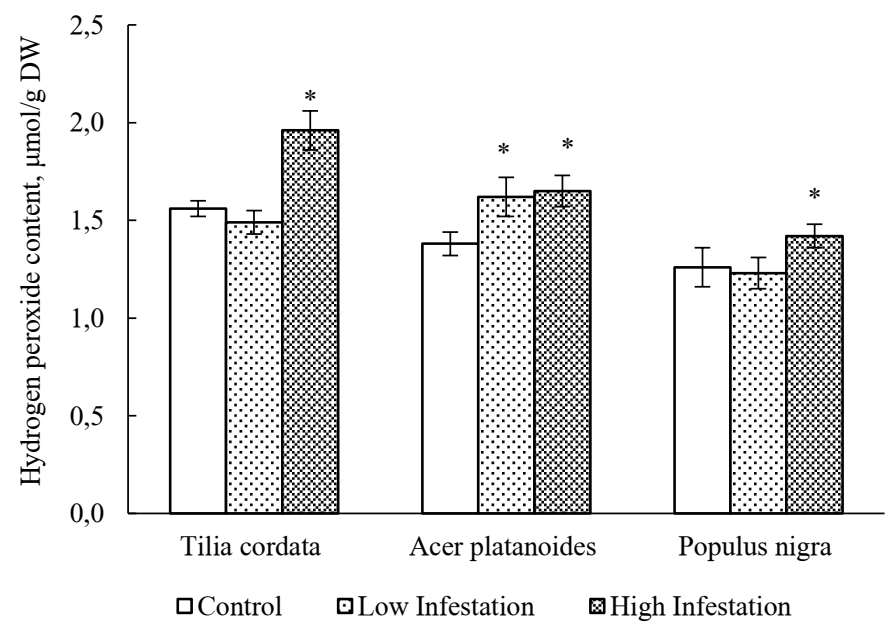


Fig. 2. The hydrogen peroxide content in the bark of control and mistletoe-infected trees of various species. * denotes significantly different mean values as compared to the control according to Tukey test at $p \leq 0.05$.

To prevent the oxidative process intensification in plant cells, the antioxidant system is activated. The plant antioxidant system includes low-molecular-weight antioxidants (e.g., ascorbic acid, reduced glutathione, proline, tocopherols) and antioxidant enzymes (e.g., superoxide dismutase, catalase, peroxidases) [12]. The results of studies of changes in superoxide dismutase (SOD) activity in mistletoe trees are shown in Figure 3. Significant changes in the activity of this enzyme were detected only in samples of Acer platanoides trees with a low infestation degree. In these samples, the SOD activity was lower compared to the control plants.

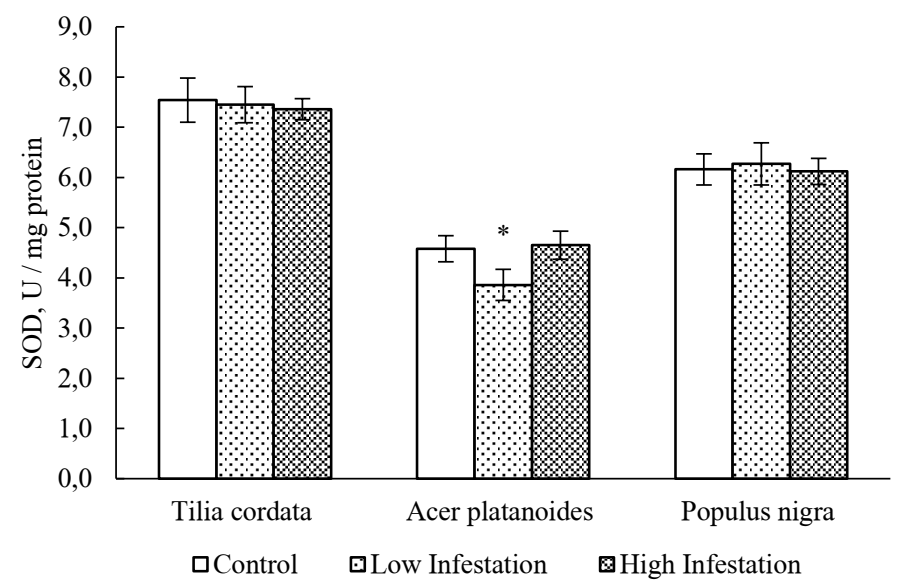

Fig. 3. The superoxide dismutase activity in the bark of control and mistletoe-infected trees of various species. * denotes significantly different mean values as compared to the control according to Tukey test at $p \leq 0.05$.

The catalase reaction, the enzyme responsible primarily for the hydrogen peroxide decomposition in cells, was more pronounced compared with superoxide dismutase (Figure 4).

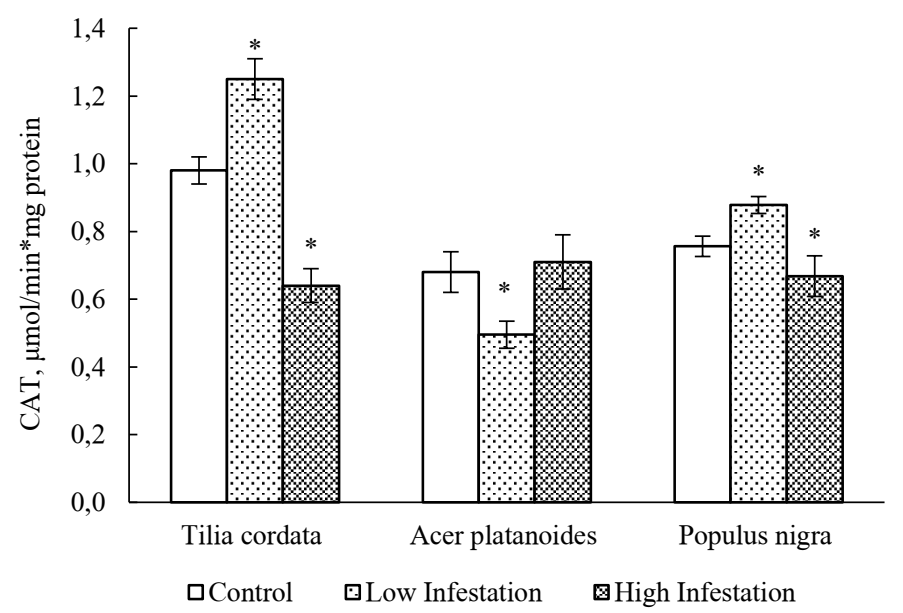


Fig. 4. The catalase activity in the bark of control and mistletoe-infected trees of various species. * denotes significantly different mean values as compared to the control according to Tukey test at $p \leq 0.05$.

For Tilia cordata and Populus nigra trees with a low degree of mistletoe damage, an increase in catalase activity was observed compared with the control (Figure 4). However, with a strong lesion of trees, the enzyme activity was lower. For Acer platanoides trees, catalase activity decreased at low infections and remained significantly unchanged compared to control trees at high levels of mistletoe lesions. Despite the fact that mistletoe is a semi-parasitic plant, there are significant changes in the primary and secondary metabolism of host trees when mistletoe is infested. These changes are largely attributed to disruption of water and mineral balance in trees $[13,14]$, which can lead to the development of oxidative stress. The increase in catalase activity detected in our study may be the result of activation of the antioxidant system to utilize $\mathrm{H}_{2} \mathrm{O}_{2}$ overproduced by cells during stress in mistletoe lesions. Earlier it was shown that catalase is an important enzyme responsible for drought hardiness of plants [15]. Thus, the change in catalase activity can indirectly confirm the hypothesis about violation of the water balance of trees when they are affected by mistletoe. However, for more accurate conclusions, additional studies are needed to investigate such physiological parameters related to water exchange as leaf water potential, transpiration and efficient water use.

\section{Conclusions}

The only method of combating mistletoe in the city remains the mechanical removal of branches affected by it, or the complete removal of tree in case of very severe damage. With the recent proliferation of mistletoe, urban plantings are becoming increasingly costly to maintain. The results obtained in this study indicate the intensification of oxidative processes when the trees Tilia cordata, Acer platanoides and Populus nigra are affected by mistletoe, which, in general, leads to a decrease in the resistance of urban trees and to the action of other unfavorable abiotic and biotic factors of the urbanized environment, and, therefore, can cause weakening or death of city trees.

\section{Acknowledgements}

The reported study was funded by Russian Foundation for Basic Research (RFBR) and the Government of the Kaliningrad region according to the research project No. 19-44-390004.

\section{References}

1. K L. Wolf, S. T. Lam, J. K McKeen, G. R.Richardson, M. van den Bosch, A. C. Bardekjian, Int. J. Environ. Res. Public Health, 17, 4371 (2020)

2. W. Dmuchowski, P.Brągoszewska, D. Gozdowski, A. H. Baczewska-Dąbrowska, T. Chojnacki, A. Jozwiak, E. Swiezewska, I. Suwara, B. Gworek, Trees 1-16 (2020)

3. L. Skrypnik, P. Maslennikov, P. Feduraev, A. Pungin, N. Belov, Plants, 9, 394 (2020)

4. H. Szmidla, M. Tkaczyk, R. Plewa, G. Tarwacki, Z. Sierota, Forests, 10, 847 (2019)

5. V. Hu, H. Sakakibara, Y. Takebayashi, F. S. Peters, J. Schumacher, M. Eiblmeier, L. Arab, J. Kreuzwieser, A. Polle, H. Rennenberg, Tree Physiol., 37, 676 (2017)

6. N Varghese, O. Alyammahi, S. Nasreddine, A. Alhassani, M.A. Gururani, Plants 8, 610 (2019) 
7. S. Sharma, G. Anand, N. Singh, R. Kapoor, Front. Plant Sci., 8, 906 (2017)

8. R. K Sairam, K. V. Rao, G.C. Srivastava, Plant Sci., 163, 1037 (2002)

9. A. M. S. A. Qados, Intl. Res. J. Agri. Sci. Soil Sci., 3, 22 (2015)

10. S. Mutlu, V. Ilhan, H. I Turkoglu, Tree Physiol., 36, 479 (2016)

11. H. Sies, D. P. Jones, Nat. Rev. Mol. Cell Biol., 21, 363 (2020)

12. P. V. Maslennikov, G. N Chupakhina, L. N Skrypnik, P. V. Feduraev, A. S.Melnik, Russ. J. Ecol., 49, 384 (2018)

13. J. J. Camarero, E. G. de Andrés, G. Sangüesa-Barreda, A.Rita, M.Colangelo, Dendrochronologia, 56, 125598 (2019)

14. A. Lázaro-González, J. A. Hódar, R. Zamora, J. Chem. Ecol., 45, 95 (2019)

15. U. Sarker, S. Oba, Sci. Rep., 8, 16496 (2018) 